\title{
AUTOSOMAL DOMINANT CEREBELLAR ATAXIAS IN THE KINKI AREA OF JAPAN
}

\author{
Ryusuke Matsumura," Tetsuya Takayanagi, Kayoko Murata, \\ Naonobu FUTAMURA, and Yasuyo FUJimoto \\ Department of Neurology, Nara Medical University, \\ 840 Shijocho, Kashihara, Nara 634, Japan
}

\begin{abstract}
Summary The autosomal dominant cerebellar ataxias are a heterogeneous group of neurodegenerative disorders characterized by slowly progressive cerebellar ataxia. Recently, among the ataxias, spinocerebellar ataxia type 1 (SCA1), Machado-Joseph disease (MJD) and dentatorubral-pallidoluysian atrophy have been found to be caused by expansion of a CAG trinucleotide repeat in the coding region of the disease genes. We have analyzed the CAG repeats of 67 patients from 47 families with dominantly inherited ataxia who lived in the Kinki area of Japan. The following results were obtained. First, 31 patients from 22 families were found to be positive for the MJD repeat expansion, indicating that MJD is the most common dominantly inherited ataxia in the Kinki area of Japan. Second, no SCA1 repeat expansion was found among the families studied. This presents a striking contrast to the fact that there are many families with SCAl in Hokkaido and the Tohoku area of Japan. These findings suggest geographic variation in autosomal dominant cerebellar ataxias in Japan.
\end{abstract}

Key Words trinucleotide repeat, CAG repeat, spinocerebellar ataxia type 1, Machado-Joseph disease, dentatorubral-pallidoluysian atrophy

\section{INTRODUCTION}

The autosomal dominant cerebellar ataxias are a heterogeneous group of neurodegenerative disorders characterized by variable combinations of cerebellar ataxia, ophthalmoplegia, pyramidal signs, extrapyramidal signs and peripheral neuropathy (Harding, 1993). The ataxias typically have onset in adult life, though there are exceptions. The clinical classification of dominantly inherited ataxias has proved difficult and unreliable due to variation and overlapping of clinical features both between and within families. In recent years, however, much progress

Received September 2, 1996; Revised version accepted October 28, 1996.

* To whom correspondence should be addressed. 
has been made toward the development of a genetic classification for the ataxias. To date, seven different gene loci causing dominantly inherited ataxia have been mapped: spinocerebellar ataxia type 1 (SCA1) on chromosome 6p22-23 (Orr et al., 1993), SCA2 on 12q23-24.1 (Gispert et al., 1993), Machado-Joseph disease (MJD)/ SCA3 on 14q32.1 (Kawaguchi et al., 1994; Twist et al., 1995), SCA4 on 16q24-ter (Gardner et al., 1994), SCA5 on the centromeric region of chromosome 11 (Ranum et al., 1994), SCA7 on 3p14-21 (Gouw et al., 1995), dentatorubral-pallidoluysian atrophy (DRPLA) on 12p12-ter (Nagafuchi et al., 1994). Among these disorders, the mutations responsible for SCA1, MJD and DRPLA have been identified as expansion of a CAG trinucleotide repeat in the coding region of the disease genes (Orr et al., 1993; Kawaguchi et al., 1994; Koide et al., 1994; Nagafuchi et al., 1994). The mechanism by which CAG repeat expansion causes neurodegeneration is unknown.

The identification of the SCA1, MJD and DRPLA mutations provided us with the means for accurate classification and diagnosis of these disorders. To elucidate the characteristics of the autosomal dominant cerebellar ataxias in the Kinki area of Japan, we have collected blood samples from 47 families with dominant ataxia and determined the frequency of the SCA1, MJD and DRPLA mutations in this area.

\section{MATERIALS AND METHODS}

Families. A total of 67 patients from 47 families were neurologically examined by the authors and considered to have an autosomal dominant cerebellar ataxia. All the families lived in the Kinki area which is located in the western part of the main island of Japan and consists of Nara, Osaka, Hyogo, Kyoto, Shiga and Wakayama Prefectures. In this study, there were no patients who lived in Wakayama Prefecture. As far as could be traced, the original residence of the 47 families was as listed in Table 1.

DNA analysis. Genomic DNA was extracted from peripheral blood lymphocytes by standard procedures. Polymerase chain reaction (PCR) for detection of

Table 1. Original residence of the 47 families with autosomal dominant cerebellar ataxia in the Kinki area.

\begin{tabular}{lcccc}
\hline Place of original residence & Total & MJD & DRPLA & SCA1 \\
\hline Kinki area & 37 & 17 & 5 & 0 \\
Shikoku area & 3 & 1 & 1 & 0 \\
Kyushu area & 3 & 2 & 0 & 0 \\
Kanto area & 2 & 2 & 0 & 0 \\
Toukai area & 1 & 0 & 0 & 0 \\
Korea & 1 & 0 & 0 & 0 \\
Total & 47 & 22 & 6 & 0 \\
\hline
\end{tabular}


the SCA1, MJD and DRPLA mutations was carried out using the following published primers: Rep1 and Rep2 for SCA1 (Orr et al., 1993), MJD52 and MJD70 for MJD (Kawaguchi et al., 1994) and CTG-B37 primers for DRPLA (Li et al., 1993; Koide et al., 1994; Nagafuchi et al., 1994). For determination of the CAG repeat length in the SCA1 and DRPLA genes, the PCR products were electrophoresed on 6\% denaturing acrylamide gels and compared with an M13 sequencing ladder according to the previous methods (Orr et al., 1993; Koide et al., 1994; Nagafuchi et al., 1994). For determination of the CAG repeat length in the MJD gene, the PCR products were directly sequenced using an automated DNA sequencer (Applied Biosystems, model 373A) as described (Matsumura et al., 1996).

\section{RESULTS}

\section{$M J D$ repeat expansion}

Of the 47 families with autosomal dominant cerebellar ataxia, 31 patients from 22 families (47\%) were found to have expanded CAG repeats in the MJD gene. Figure la shows the distribution of CAG repeat length in normal and expanded alleles of the 31 patients. Normal alleles ranged from 14 to 37 repeats, with a peak at 14 repeats in 15 (48\%) of the patients. Expanded alleles ranged from 64 to 84 repeats (mean $\pm S D=74.7 \pm 4.2$ ). All the patients were heterozygous for the MJD mutation, with one allele in the mutated range and the other in the normal range. The mean age of onset of the 31 patients was $38.6 \pm 11.4$ years, with a range of 13 to 60 . Figure $2 \mathrm{a}$ shows the relationship between the age of onset and the repeat length in the MJD gene. We found a significant inverse correlation between these two factors $(\mathrm{r}=-0.830, \mathrm{p}<0.0001)$. Juvenile onset MJD individuals $($ age $<20$ ) had 81 to 84 repeats, while late onset (age $>50$ ) showed 69 to 70 repeats.

\section{DRPLA repeat expansion}

Ten patients from six families (13\%) were positive for the DRPLA trinucleotide repeat expansion. Figure $1 \mathrm{~b}$ shows the distribution of CAG repeat length in normal and expanded alleles of the 10 patients. Expanded alleles had 57 to 72 repeats, whereas normal alleles had 10 to 19 repeats. All the patients were heterozygous for the DRPLA mutation. As is the case with MJD, a significant inverse correlation ( $\mathrm{r}=-0.840, \mathrm{p}=0.0024)$ was observed between the age of onset and the repeat length in the DRPLA gene (Fig. 2b).

\section{SCA1 repeat expansion}

No SCA1 repeat expansion was found among the families studied. Every subject had two normal alleles with less than 37 repeats in the SCAl gene. Sequence analysis of the largest allele (36 repeats) revealed that the CAG repeat tract was interrupted by two CAT trinucleotides (data not shown). This finding is 


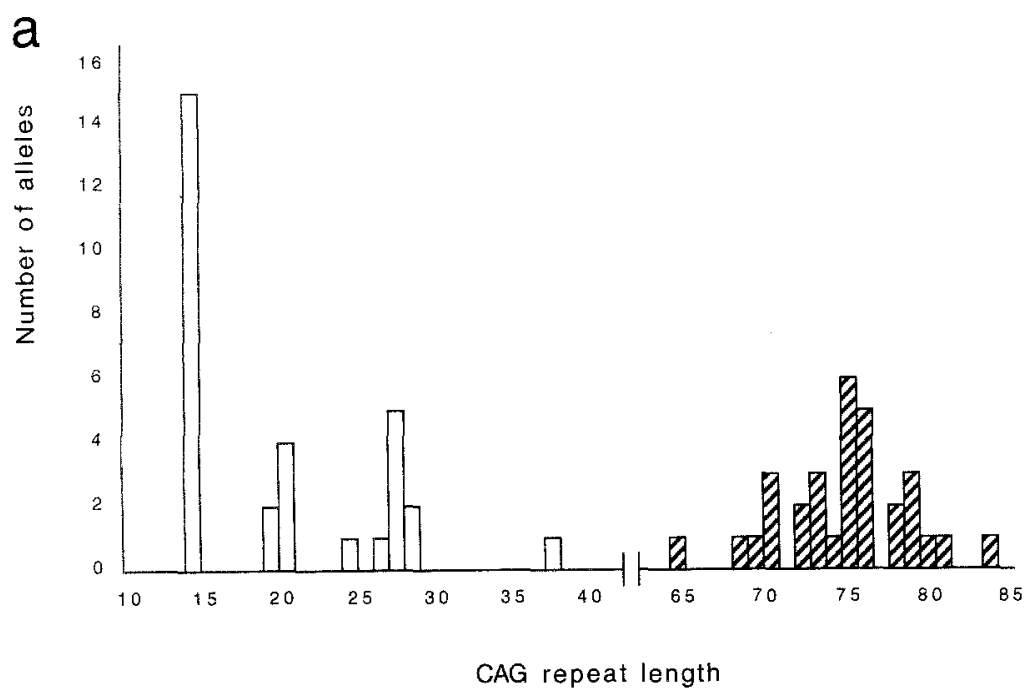

b

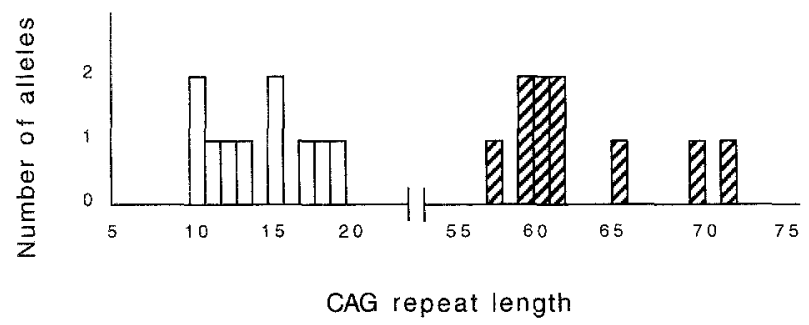

Fig. 1. Distribution of CAG repeat length in the MJD gene (a) and the DRPLA gene (b). Thirty-one MJD patients (a) and 10 DRPLA patients (b) were studied. Open bars represent normal alleles; hatched bars, expanded alleles.

consistent with the characteristics of normal alleles previously reported (Chung et al., 1993).

The remaining 26 patients from 19 families were not classified as either MJD, DRPLA or SCA1. These families were too small to carry out linkage analysis for other disease loci such as SCA2, SCA4 and SCA5.

\section{DISCUSSION}

To assess the frequency of the MJD, DRPLA and SCAl mutations in the Kinki area of Japan, we studied 47 families with dominant ataxia who lived in this area. The following results were obtained. First, approximately half of the families were found to be positive for the MJD repeat expansion, indicating that MJD is the most common dominantly inherited ataxia in the Kinki area of Japan. Second, no SCA1 repeat expansion was found among the families. This presents a striking 

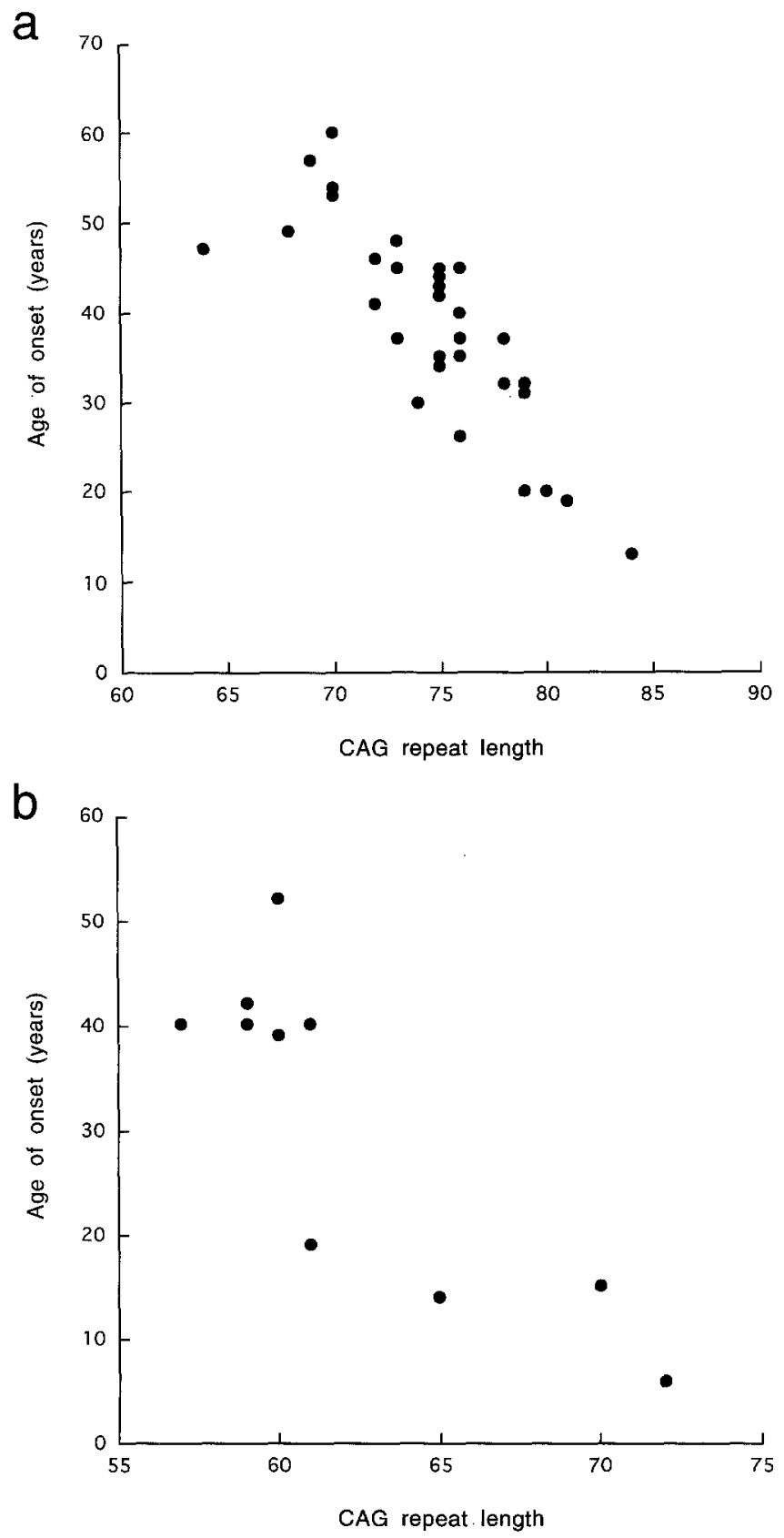

Fig. 2. Correlation between age of onset and CAG repeat length in MJD (a) and DRPLA (b).

contrast to the fact that there are many families with SCA1 in the Tohoku area and Hokkaido both of which are located in the northern part of Japan (Kameya et al., 
1995; Suzuki et al., 1995). Among 25 families with dominant ataxia in the Tohoku area, $48 \%$ were positive for the SCA1 mutation, whereas $32 \%$ showed the MJD repeat expansion (Kameya et al., 1995). This finding suggests that not MJD but SCA1 is the most common dominant ataxia in the Tohoku area. In Hokkaido, 10 SCA1 families have been reported. Interestingly, detailed haplotype analysis suggested that SCAl in Hokkaido derives from a single common ancestry in the Tohoku area (Wakisaka et al., 1995). In our study, no family migrated from the Tohoku area where the SCAl mutation is frequent (Table 1). Most families originated from the Kinki area. Although our study did not contain all of the families with dominant ataxia in the Kinki area, we can conclude that the SCA1 mutation is rare in the Kinki area. Thus, these findings suggest geographic variation in autosomal dominant cerebellar ataxias in Japan. This variation may reflect the distribution of ancestral mutations of the diseases.

Ranum et al. (1995) studied the frequency of the SCA1 and MJD mutations in 149 dominant ataxia families with different ethnic backgrounds such as African-American, Caucasian-American and Asian. Of these, 3\% had the SCA1 repeat expansion and $21 \%$ were positive for the MJD repeat expansion. Screening for the DRPLA mutation was not carried out. Similarly, Silveira et al. (1996) reported that among 29 families with dominant ataxia collected from North America, India and Brazil, the frequencies of the SCAI and MJD mutations were $10 \%$ and $17 \%$, respectively. The DRPLA mutation was found only in one family of Japanese origin. To date, only six families with DRPLA have been reported in non-Japanese populations (Burke et al., 1994; Potter et al., 1995; Warner et al., 1995). In contrast, six families in the Kinki area (this study) and 40 families in other areas of Japan (Ikeuchi et al., 1995; Komure et al., 1995) were positive for the DRPLA repeat expansion. Thus, the DRPLA mutation seems to be common only in the Japanese. We could not compare the frequency of the DRPLA mutation in the Kinki area with that in other areas of Japan because we had little information on addresses of the 40 families with DRPLA reported elsewhere.

Distributions of CAG repeat length in expanded alleles from MJD and DRPLA patients in the Kinki area were similar to those previously reported (Ikeuchi et al, 1995; Komure et al., 1995; Maciel et al., 1995; Maruyama et al., 1995; Takiyama et al., 1995). We also found a significant inverse correlation between the age of onset and the repeat length in both MJD and DRPLA. These findings indicate that the MJD and DRPLA repeat expansions in the Kinki area have the same molecular basis as those in other areas of Japan and foreign countries.

The cloning of the MJD, DRPLA and SCA1 genes allowed us to make an accurate diagnosis in families too small for linkage analysis. However, $40 \%$ of the families in our study were not classified as either of these diseases. Therefore, the genes responsible for SCA2, SCA4, SCA5 and SCA7 need to be identified. 
Acknowledgments This work was supported in part by a Grant-in-Aid for Intractable Disease, Ministry of Health and Welfare of Japan, and a Grant-in-Aid from The Science and Technology Agency of Japan. We are grateful to the subjects who participated in this research and to Professor Richard F. Mayer, University of Maryland School of Medicine, Baltimore, MD, for critical reading of the manuscript.

\section{REFERENCES}

Burke JR, Wingfield MS, Lewis KE, Ross AD, Lee JE, Hulette C, Pericak-Vance MA, Vance JM (1994): The Haw river syndrome: Dentatorubropallidoluysian atrophy (DRPLA) in an African-American family. Nature Genet 7: 521-524

Chung M, Ranum LPW, Duvick LA, Servadio A, Zoghbi HY, Orr HT (1993): Evidence for a mechanism predisposing to intergenerational $\mathrm{CAG}$ repeat instability in spinocerebellar ataxia type 1. Nature Genet 5: 254-258

Gardner K, Alderson K, Galster B, Kaplan C, Leppert M, Ptacek L (1994): Autosomal dominant spinocerebellar ataxia: Clinical description of a distinct hereditary ataxia and genetic localization to chromosome 16 (SCA4) in a Utah kindred. Neurology 44 (Suppl 2): A361

Gispert S, Twells R, Orozco G, Brice A, Weber J, Heredero L, Scheufler K, Riley B, Allotey R, Nothers C, Hillermann R, Lunkes A, Khati C, Stevanin G, Hernandez A, Magariño C, Klockgether T, Durr A, Chneiweiss H, Enczmann J, FarralI M, Beckmann J, Mullan M, Wernet P, Agid Y, Freund H-J, Williamson R, Auburger G, Chamberlain S (1993): Chromosomal assignment of the second locus for autosomal dominant cerebellar ataxia (SCA2) to chromosome 12q23-24.1. Nature Genet 4: 295-299

Gouw LG, Kaplan CD, Haines JH, Digre KB, Rutledge SL, Matilla A, Leppert M, Zoghbi HY, Ptâcek LJ (1995): Retinal degeneration characterizes a spinocerebellar ataxia mapping to chromosome 3p. Nature Genet 10: 89-93

Harding AE (1993): Clinical features and classification of inherited ataxias. Adv Neurol 61: 1-14

Ikeuchi T, Koide R, Tanaka H, Onodera O, Igarashi S, Takahashi H, Kondo R, Ishikawa A, Tomoda A, Miike T, Sato K, Ihara Y, Hayabara T, Isa F, Tanabe H, Tokiguchi S, Hayashi M, Shimizu N, Ikuta F, Naito H, Tsuji S (1995): Dentatorubral-pallidoluysian atrophy: Clinical features are closely related to unstable expansions of trinucleotide (CAG) repeat. Ann Neurol 37: 769-775

Kameya T, Abe K, Aoki M, Sahara M, Tobita M, Konno H, Itoyama Y (1995): Analysis of spinocerebellar ataxia type 1 (SCAl)-related CAG trinucleotide expansion in Japan. Neurology 45: $1587-1594$

Kawaguchi Y, Okamoto T, Taniwaki M, Aizawa M, Inoue M, Katayama S, Kawakami H, Nakamura S, Nishimura M, Akiguchi I, Kimura J, Narumiya S, Kakizuka A (1994): CAG expansions in a novel gene for Machado-Joseph disease at chromosome 14q32.1. Nature Genet 8: $221-228$

Koide R, Ikeuchi T, Onodera O, Tanaka H, Igarashi S, Endo K, Takahashi H, Kondo R, Ishikawa A, Hayashi T, Saito M, Tomoda A, Miike T, Naito H, Ikuta F, Tsuji S (1994): Unstable expansion of CAG repeat in hereditary dentatorubral-pallidoluysian atrophy (DRPLA). Nature Genet 6: 9-13

Komure O, Sano A, Nishino N, Yamauchi N, Ueno S, Kondoh K, Sano N, Takahashi M, Murayama N, Kondo I, Nagafuchi S, Yamada M, Kanazawa I (1995): DNA analysis in hereditary dentatorubral-pallidoluysian atrophy: Correlation between CAG repeat length and phenotypic variation and the molecular basis of anticipation. Neurology 45: 143-149

Li S-H, McInnis MG, Margolis RL, Antonarakis SE, Ross CA (1993): Novel triplet repeat containing genes in human brain: Cloning, expression, and length polymorphisms. Genomics 16: $572-579$

Maciel P, Gaspar C, DeStefano AL, Silveira I, Coutinho P, Radvany J, Dawson DM, Sudarsky L, Guimarães J, Loureiro JEL, Nezarati MM, Corwin LI, Lopes-Cendes I, Rooke K, Rosenberg R, MacLeod P, Farrer LA, Sequeiros J, Rouleau GA (1995): Correlation between 
CAG repeat length and clinical features in Machado-Joseph disease. Am $\mathbf{J}$ Hum Genet 57: $54-61$

Maruyama H, Nakamura S, Matsuyama Z, Sakai T, Doyu M, Sobue G, Seto M, Tsujihata M, Oh-i T, Nishio T, Sunohara N, Takahashi R, Hayashi M, Nishino I, Ohtake T, Oda T, Nishimura M, Saida T, Matsumoto H, Baba M, Kawaguchi Y, Kakizuka A, Kawakami H (1995): Molecular features of the CAG repeats and clinical manifestation of Machado-Joseph disease. Hum Mol Genet 4: 807-812

Matsumura R, Takayanagi T, Fujimoto Y, Murata K, Mano Y, Horikawa H, Chuma T (1996): The relationship between trinucleotide repeat length and phenotypic variation in MachadoJoseph disease. J Neurol Sci 139: 52-57

Nagafuchi S, Yanagisawa H, Sato K, Shirayama E, Ohsaki E, Bundo M, Takeda T, Tadokoro K, Kondo I, Murayama N, Tanaka Y, Kikushima H, Umino K, Kurosawa H, Furukawa T, Nihei K, Inoue T, Sano A, Komure O, Takahashi M, Yoshizawa T, Kanazawa I, Yamada M (1994): Dentatorubral and pallidoluysian atrophy expansion of an unstable CAG trinucleotide on chromosome 12p. Nature Genet 6: 14-18

Orr HY, Chung M, Banfi S, Kwiatkowski TJ Jr, Servadio A, Beaudet AL, McCall AE, Duvick LA, Ranum LPW, Zoghbi HY (1993): Expansion of an unstable trinucleotide CAG repeat in spinocerebellar ataxia type 1. Nature Genet 4: 221-226

Potter NT, Meyer MA, Zimmerman AW, Eisenstadt ML, Anderson IJ (1995): Molecular and clinical findings in a family with dentatorubral-pallidoluysian atrophy. Ann Neurol 37: 273277

Ranum LPW, Lundgren JK, Schut LJ, Ahrens MJ, Perlman S, Aita J, Bird TD, Gomez C, Orr HT (1995): Spinocerebellar ataxia type 1 and Machado-Joseph disease: Incidence of CAG expansions among adult-onset ataxia patients from 311 families with dominant, recessive, or sporadic ataxia. Am J Hum Genet 57: 603-608

Ranum LPW, Schut LJ, Lundgren JK, Orr HT, Livingston DM (1994): Spinocerebellar ataxia type 5 in a family descended from the grandparents of President Lincoln maps to chromosome 11. Nature Genet 8: 280-284

Silveira I, Lopes-Cendes I, Kish S, Maciel P, Gasper C, Coutinho P, Botez MI, Teive H, Arruda W, Steiner CE, Pinto-Junior W, Maciel JA, Jain S, Sack G, Andermann E, Sudarsky L, Rosenberg R, MacLeod P, Chitayat D, Babul R, Sequeiros J, Rouleau GA (1996): Frequency of spinocerebellar ataxia type 1, dentatorubropallidoluysian atrophy, and Machado-Joseph disease mutations in a large group of spinocerebellar ataxia patients. Neurology 46: 214-218

Suzuki Y, Sasaki H, Wakisaka A, Takada A, Yoshiki T, Iwabuchi K, Tashiro K, Fukazawa T, Hamada T (1995): Spinocerebellar ataxia 1 (SCA1) in the Japanese: Analysis of CAG trinucleotide repeat expansion and instability of the repeat for paternal transmission. Jpn $J$ Human Genet 40:131-143

Takiyama Y, Igarashi S, Rogaeva EA, Kondo K, Rogaev EI, Tanaka H, Sherrington R, Sanpei K, Liang Y, Saito M, Tsuda T, Takano H, Ikeda M, Lin C, Chi H, Kennedy JL, Lang AE, Wherrett JR, Segawa M, Nomura Y, Yuasa T, Weissenbach J, Yoshida M, Nishizawa M, Kidd KK, Tsuji S, St George-Hyslop PH (1995): Evidence for inter-generational instability in the $C A G$ repeat in the $M J D l$ gene and for conserved haplotypes at flanking markers amongst Japanese and Caucasian subjects with Machado-Joseph disease. Hum Mol Genet 4: 1137-1146

Twist EC, Casaubon LK, Ruttledge MH, Rao VS, Macleod PM, Radvany J, Zhao Z, Rosenberg RN, Farrer LA, Rouleau GA (1995): Machado-Joseph disease maps to the same region of chromosome 14 as the spinocerebellar ataxia type 3 locus. J Med Genet 32: 25-31

Wakisaka A, Sasaki H, Takada A, Fukazawa T, Suzuki Y, Hamada T, Iwabuchi K, Tashiro K, Yoshiki T (1995): Spinocerebellar ataxia 1 (SCA1) in the Japanese in Hokkaido may derive from a single common ancestry. J Med Genet 32: 590-592

Warner TT, Williams LD, Walker RWH, Flinter F, Robb SA, Bundey SE, Honavar M, Harding AE (1995): A clinical and molecular genetic study of dentatorubropallidoluysian atrophy in four European families. Ann Neurol 37: 452-459 